\title{
EMERGENT PRINCIPLES FOR DIGITAL DOCUMENTARY
}

\author{
Richard Lachman \\ RTA School of Media \\ Ryerson University \\ 350 Victoria St \\ Toronto, ON M5B 2K3 \\ Canada \\ richlach@ryerson.ca
}

\begin{abstract}
Digital Documentaries are an area of rapid invention and experimentation at all levels, including creative content, production techniques, and business models. As with many forms of digital storytelling, a focus on technologies can be distracting; platforms change rapidly, and are dependent on external commercial forces rather than creative potential. This article presents several design strategies for driving experimentation in digital documentary above and beyond the specific of platform and technology. The core focus is on treating digital docs as experiences, with an expanded range of designable moments, as well as a strategic approach to designing interactions. The discussion is not intended to fully characterize digital documentary design factors, but rather, defines a useful subset of methods that can lead emerging practitioners to new innovations and approaches.
\end{abstract}

Keywords: digital documentary, transmedia documentary, experience design

\section{Introduction}

Grierson famously defined documentary as "the creative treatment of actuality". ${ }^{1}$ That general description belies the wealth of filmic approaches, techniques, moods, themes, and styles in documentary, with an equivalent range in photography or audio. Nichols $(2010)^{2}$ discusses the fluid boundaries and creative spirit of the form and its practitioners, which is absolutely carried on in the vibrant experimentation we see in the digital form. Digital documentaries have been an area of great interest for creators, festivals, and audiences, while at the same time blurring ideas of form, intention, technique, and genre. Yet Almeida and Alvelos, in "An Interactive Documentary Manifesto", decry the application of the term to every multimedia video project; they call for creators to move beyond remediation, to embrace more of the potential of interactive media as well as a documentary ethos. ${ }^{3}$ What is that potential, that unique approach which separates a digital documentary from a more conventionally-realized one?

The vast range of projects included as digital documentary would be impossible to characterize in a short article such as this. Indeed, there is such creative inventiveness at play that any such attempt would be rapidly out of date. The terms of art

1 John Grierson, Grierson on Documentary, University of California Press, 1966.

2 Bill Nichols, Introduction to Documentary (Second ed.), Indiana University Press, 2010.

3 Andre Almeida and Heitor Alvelos, 'An interactive documentary manifesto,' Joint International Conference on Interactive Digital Storytelling,

Springer, 2010. 
("digital documentary", "i-doc", "web-doc") are used to describe web-based narratives, games, installations, database-driven works, user-generated content, and a wealth of other initiatives that all lay claim to Nichol's legacy. The reader is directed to projects such as Docubase by MIT's OpenDoc Lab (http://docubase.mit.edu/) and the i-Docs community (http://i-docs. org/) for more discussion of the range and constituency contained with digital documentary. Instead, this article will explore some key emergent principles that practitioners can use as launch-points for their explorations, gleaned from the author's years as a researcher and creator in the field, as well as six years teaching Digital Documentary Production at the graduate level. The focus will remain on screen-based works that incorporate media in their core narrative.

\section{Medium Specificity and Affordances}

In my experience, many documentarians come to digital storytelling from a conventional media background, with deep knowledge of a particular traditional-media form. They may approach their digital opportunity with a combination of trepidation and doubt about how that knowledge applies, or, conversely, blind trust that a software-developer can work magic the documentarian just doesn't understand. I've found it important to help new converts explore how their existing instincts might inform their digital works. Ultimately, it's the documentary ethos that should drive the work, rather than the technical, and that requires documentarians to explicitly interrogate their own practice in this new context.

While somewhat controversial in art and media circles, the lens of media specificity explores how creative, consumptive, and industrial characteristics can shape production within any specific media form. ${ }^{4}$ This can include the way serialization affects storytelling in television (versus, say, film), or the role of a reader's imagination in a novel (versus, say, radio-drama). Janet Murray ${ }^{5}$ describes the affordances of digital works (that is, the properties of the form that suggest particular uses), as follows:

- Procedural: conditional instructions, with a sequence of cause-and-effect actions that respond to inputs.

- Participatory: involving the actions of the user directly in the process; also has the potential to involve distributed groups of users.

- Encyclopedic: the ability to have a vast corpus of content, of formats, or system-simulations, which can be presented according to a variety of organizational principles

- Spatial: principles of organizing content with a spatial metaphor, following traditional strategies (maps, 3D),or more innovative schemes.

It is these particular capabilities that speak to Almeida and Alvaros' call for projects that explore the unique aspects of interactive non-fiction. When these affordances are tightly integrated into the design and the story, it becomes impossible to imagine the same work as a linear film.

\section{Interactivity and Experience}

Why does one want to add "interactivity" to a project? What does one gain and lose? For documentarians, there is often an ill-defined hope that the user will be more engaged if they have control over aspects of what they experience. This term, engagement, is used vaguely, often as a catchall for the dream of a passionate (and profitable, or at least numerous) audience. In the literature, engagement can combine sensory appeal, control, motivation, aesthetics, and goal-seeking, and may go through multiple stages with distinct characteristics. ${ }^{6}$ In early stages, aesthetics may draw an audience in; if 
interaction continues, however, an awareness of how their actions impact the experience (control and feedback), and a connection to the technology (interaction) or other people (social awareness) may be needed to maintain interest. In the early days of convergent-media projects, digital documentary extensions simply made un-edited or "extended" versions of interviews available for download. The designers seemed to hope 'having choice' would result in the elusive audience engagement. As might be expected, this abdication of the editing process didn't lead to critical success or extraordinary site-visit numbers, and the field moved on. Any project needs to begin with the question "why is this interactive?" If it is possible to do the work as a linear, traditional-media project, then one should do so. Linear media is a mature form, with many more referents to suggest techniques that can accomplish the goals of a storyteller. There needs to be a driving reason, a way that the interactive approach adds a dynamic fundamental to the handling of the narrative.

\section{The Promise of Interactivity}

Let's reduce an interaction down to very simple mechanisms - say, a scrolling mouse-wheel, or, on a tablet/touchpad, a vertical drag. In projects such as the New York Times SnowFall ${ }^{7}$ and its' more evolved successor, A Game of Shark and Minnow, ${ }^{8}$ the main interface is simply to advance or retreat with a scroll-wheel. The user moves through a text-heavy online-newspaper-article that is enhanced byevocative media that fades in, providing texture and evoking mood to give context to the content. Parallax-scrolling media is triggered at the user's chosen pace, with animations, videos, audio, or other transitions controlled by that forward/backward interaction.

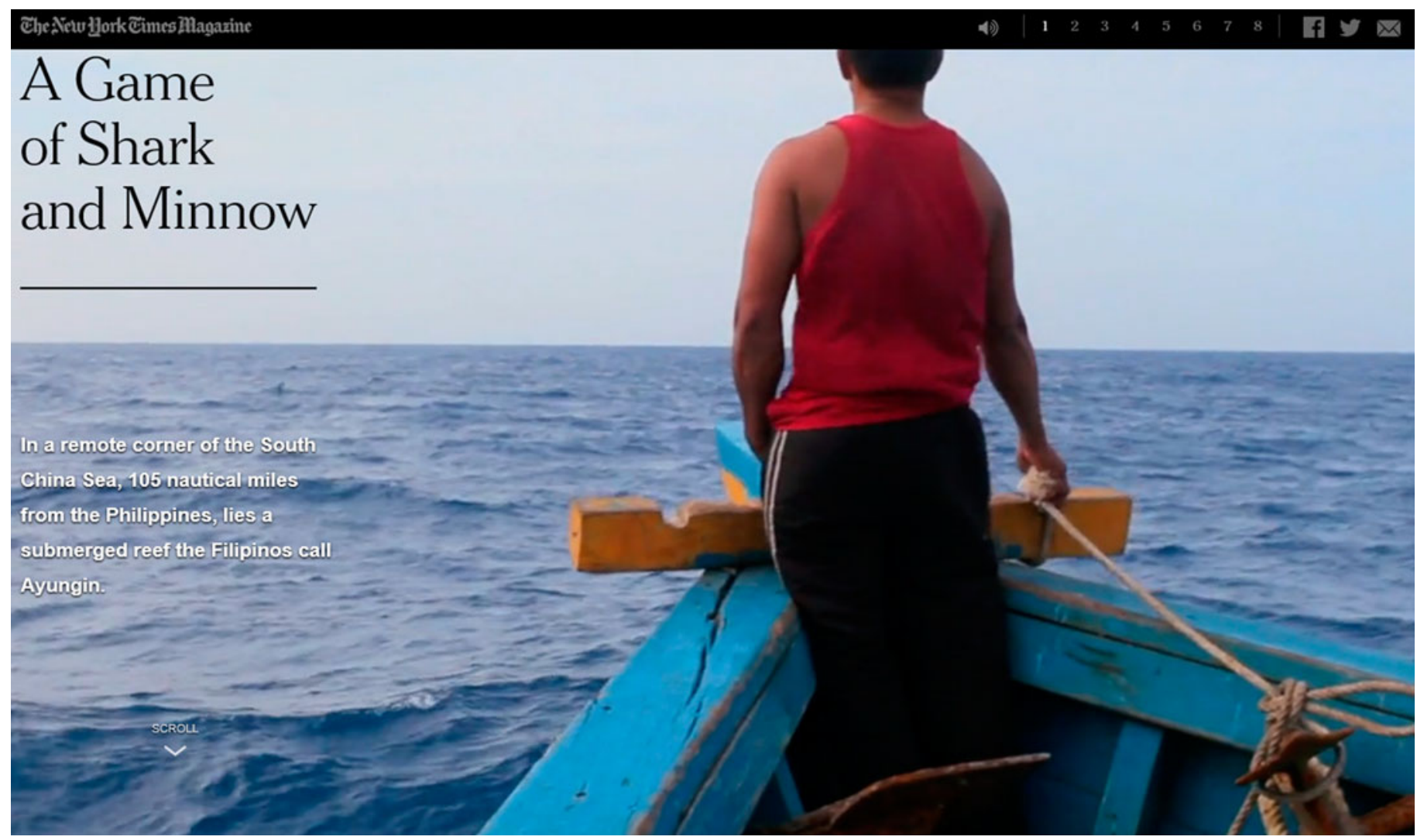

A Game of Shark and Minnow (New York Times)

7 John Brand, 'Snow Fall: The Avalanche at Tunnel Creek,' New York Times Magazine, 2012, http://www.nytimes.com/projects/2012/snow-fall/. 8 Jeff Himmelman, 'A Game of Shark and Minnow,' New York Times Magazine, 2013, http://www.nytimes.com/newsgraphics/2013/10/27/southchina-seal. 
This simple single control, however, can reveal a wealth of motivating factors about interactivity in general. The user experiences a certain amount of surprise, of wonder: they don't necessarily know what they will find next. However, there isn't any fear or confusion: they know precisely what their role is, what is expected of them. The only decision they have to make is when to scroll. That tension - wonder versus fear, unpredictability versus confusion, is what can be at the heart of the user experience in a digital project. The essence of this experience has elements of playfulness ${ }^{9}$ and sensory immersion, ${ }^{10}$ as transitions mix audio, map visualizations, subtly animated stills/videos, and text, in a novel presentation. At release, the Times' projects may have been the first time users had seen low-resolution, subtlyanimated, full-screen web-video integrated not as talking-head interview but, rather, for texture and tone. The video and audio triggered by the user adds an environmental effect, and serves to create a rich-media presence that enhances the text-based storytelling instead of competing with it.

Similarly, the digital documentary Hollow ${ }^{11}$ uses mouse-scrolling as it's main interface-technique - first on it's own, then bringing in additional interface elements such as video-controls and social media widgets as the experience progresses. This gentle introduction to the interface is further paid off with beautiful design, media, and story elements, including photo-collages that fade in under user control. Only as the user begins to better understand their role does the interface add complexity. At the same time, the content of the story itself becomes more complex, moving from an introductory overview-timeline to more substantial engagement with character and narrative. This multi-stage approach is worth exploring. When we think through the experience of the user, of how they feel at each stage, we're able to tune the experience by tuning interface, expectations, pacing, and communication strategy. How does the user feel when first arriving at the piece? What do they know already, and what do you want to convey in those first few seconds?

\section{The Cold Open}

At the beginning of a film, the creator of course encounters uncertainty in their audience, and will use various strategies to invite them into the story. Even if the audience doesn't know much about the subject matter or director's style, their role is still very clear. They know what to do: sit and watch (and perhaps, if the director is lucky, think). With digital projects, this uncertainly can be all-encompassing. The user may not know what's expected of them, what they need to do, or what the rules-of-engagement with the interface will be.

With many digital documentary projects, the interface is a new invention. A novel interaction-strategy is often part of the design approach, and is often a huge part of the impact of the entire project. The new, the 'design-y', the stylish - at best, the interface is intimately tied to the impact of the experience; at worst, the interface is overdesigned, highconcept, and opaque. In either case, the experience of the first (and sometimes only) few minutes a user spends with the project is one of discovery. The user needs to learn how to interact with this particular project, which is often unlike any other digital or analogue experience they might have had. While there are a few emerging forms and conventions (parallax scrolling, 360 video), and some creators use the same strategies in multiple projects (for example, split-screen side-by-side contrasting interviews in Upian's Gaza/Sderot ${ }^{12}$ and Havana/Miami ${ }^{13}$ ), most projects are unlike one another in basic interface. And, even if there are similarities, the user comes to each project cold, following a weblink or a forwarded recommendation. How, then, can a creator introduce the story and the interface to the user without boring them?

The time-pressure to win over with audiences before they move on is common across all digital properties. Creators may have very little time to draw users into the larger work, and little time to turn a casual visitor into a commited user. Introduction or help screens may be very off-putting, and don't use the power of the story itself to draw the user into

9 Brigid Costello and Ernest Edmonds, 'A study in play, pleasure and interaction design,' Proceedings of the 2007 conference on Designing pleasurable products and interfaces, ACM, 2007.

10 Brenda Laurel, Computers as Theatre, Addison, 1991.

11 Elaine McMillion, 'Hollow: An Interactive Documentary and Discussion,' 2014, http://hollowdocumentary.com/.

12 Alexandre Brachet, 'Gaza/Sderot: Life in Spite of Everything, online documentary,' Arte and Upian, 2008, http://gaza-sderot.arte.tv/.

13 Alexandre Brachet, 'Havana/Miami, online documentary,' Arte and Upian, 2010. 


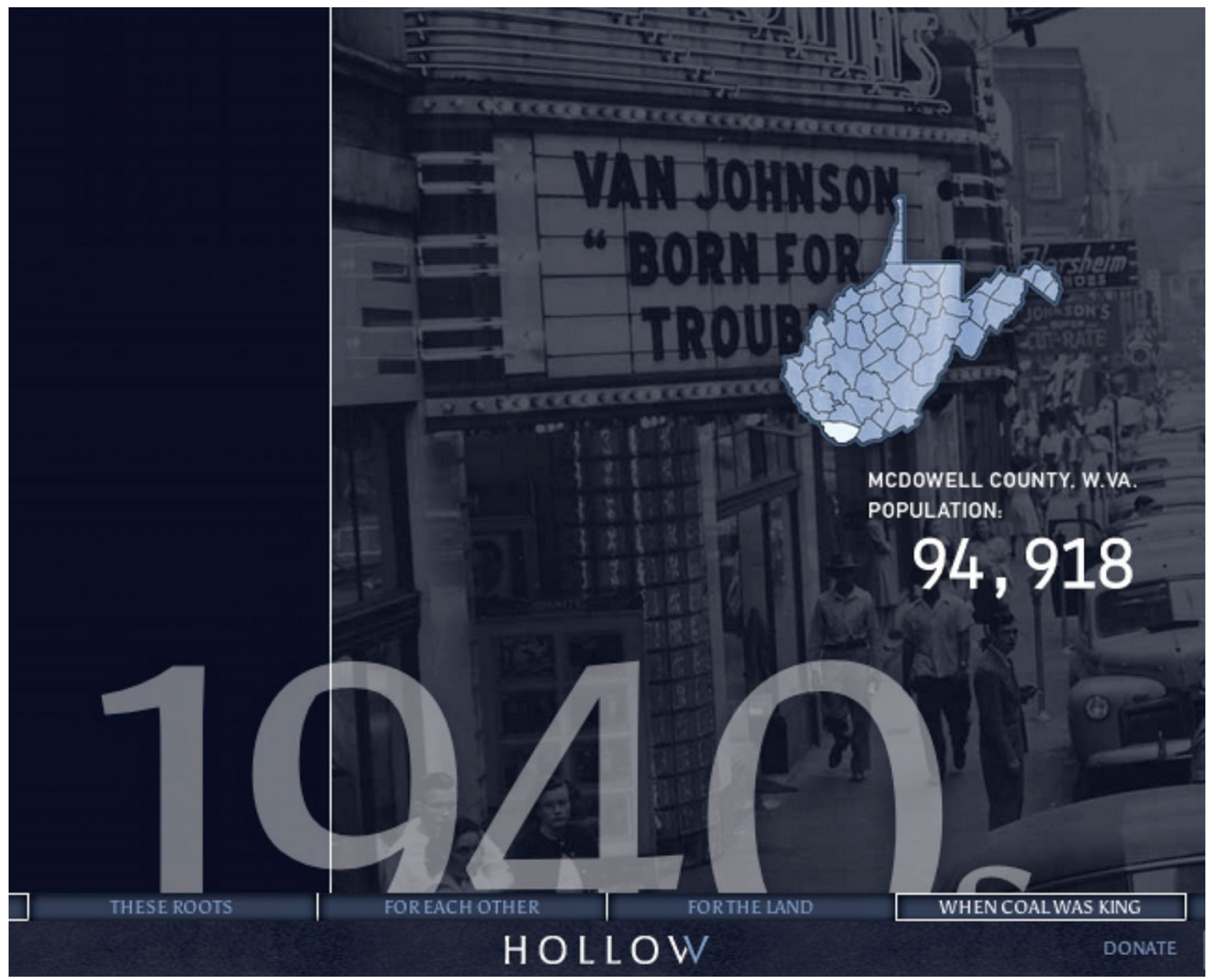

Hollow: An Interactive Documentary (Elaine McMillion Sheldon)

more commitment to the project. As described above, Hollow teaches the user the core interaction strategy with a sequence that doesn't feel like an instruction-screen, yet fulfills the same purpose. The user isn't overwhelmed with controls, and the basic instruction is accomplished within a simplified environment integrally tied to the demands of the story.

In television writing, a cold open is when a show starts right into the story, without opening credits or theme song. ${ }^{14}$ The goal is for the storyline to interest an uncommitted viewer right away, chaining a new show onto the end of a previous one, much as Netflix does when auto-playing next-episodes in a series. With a digital project, getting the user directly into a meaningful, powerful, or well-designed part of the experience can be incredibly valuable. With a limited time before users click away to the next digital distraction, designs that don't rely on complex instructions are helpful. Using the cold-open principle of jumping a user directly into compelling content, with any instruction integrated directly into content, is a principle that more digital doc projects could leverage. 


\section{Experience Design Model}

When we think of digital works as experiences rather than media productions, we expand the palette of options for understanding and influencing how people connect with them. In traditional film, the creator may feel responsible only for what's 'in the can' - the intensive work that results in the film itself. The marketing and distribution may be outside their job description, or at least a separate and distinct phase unconnected to the creative work itself. For digital projects, these processes are less easily separable. Financing may be intimately connected with pre-production and social engagement, with successful Kickstarter or other crowdfunding campaigns requiring polished media and fan coordination. How people get to a project, and the pre-conceptions they may bring with them aren't a given; they aren't watching because they happened to tune in to the public broadcaster channel on their cable box. The creator can and should think through the entire process of discovery, interaction, and sharing of the content, as so much of the traditional-media machinery that governs these processes simply doesn't exist in the digital world.

Conifer Research uses a Five E's model of experience design to expand our understanding of products as experiences.$^{15}$ Extending our sense of which parts of the experience we can design is always important, but the highly experimental nature of digital docs make this a priority.

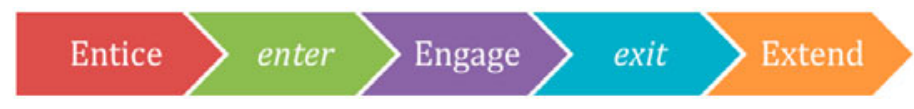

The Five E's Model of Experience Design

- Entice: how does a user find out about a digital doc? Is it a link, forwarded by a friend? Is it connected with some outside signifier of quality (Canada's NFB, a newspaper, a broadcaster)? Was a rich-media preview part of the social-media link, or was it text-only? What do I know and what is enticing about the type of experience, above and beyond the nature of the subject matter? Does it try to intrigue me by showing rather than telling? When there are few established conventions, and even fewer established distributors, this stage can set expectations that need to then be paid off in later stages.

- Enter: How does the experience start? Does it address the unique set of design problems in a way that is, itself, interesting to me? Or does a splash screen stop my interest cold, counting on later compelling content to keep me around - content that, with a bad enter-phase, I may never get to? What is signaled about the nature or length of the remainder of the experience? Do I need instructions to understand the interface? Is there a long loadingprocess, or an app-install, and if so, can I make that process part of my project?

- Engage: The core interaction (and the part most creators think of as the only part of their project

- Exit: How do I know when I'm done? Do I leave because I've completed what was made, because I'm bored, because I'm confused, or because I don't understand? If I know I haven't consumed all of the content, is that a positive experience (eg: "It's wonderful that this archive is so vast"), or a negative one ("I'm just leaving in the middle because I'm bored")? Projects like Bear 71 show a total-time estimate to the user. ${ }^{16}$ Does having that estimate make me feel more comfortable about what l'm getting into? About how much content there is left to see? How do I feel if I leave before the time runs out?

- Extend: Is it easy for me to share this with friends? Is there a compelling format or way for me to share? Is there a way to deep-link to elements, if there's a particular part I want to direct a friend to? Is there a simple, compelling action for me to take towards, say, social change, a donation, or a commitment? Is there a touchpoint that allows me to revisit some elements? How realistic is it that I will follow through on that touchpoint?

15 Conifer Research, 'How to find Buried Treasure using Experience Maps,' 2004, https://msu.edu/ jmonberg/491/User_files/ConiferExperienceMaps.pdf.

16 Leanne, Allison and Jeremy Mendes, 'Bear 71,' [Multi-format interactive], National Film Board of Canada, 2012, http://bear71.nfb.ca/\#/bear71. 
The Five E's model applies to almost anything we design, but it has particular meaning for digital documentary creators. The works they create are more likely to be unique, and exist outside traditional broadcast/distribution infrastructure. The thought-process for designing how users find, are introduced to, end, leave, and share the works becomes integral to the success of the project, above and beyond the design of the core experience itself. Each stage represents an opportunity for the creator to influence how their users connect with the work, the popularity of the project, and the impact of the message.

\section{Experience versus Narrative}

For some digital doc projects it's possible to create content with no assumption that any user will experience all of it. Archive- or map-based projects don't require a visitor to click on every link to be successful in their mission. The Diamond Road Online project had 8 hours of video divided into 3-minute segments, yet it isn't marketed to the user as an 8-hour experience. ${ }^{17,18}$ Instead, the project allows users to choose which videoclip to view next, providing contextually relevant recomendations as the user wanders through tagged and annotated micro-narratives. The model is for the user to follow their own interests around a vast interconnected database, exploring one of what feels like an unbounded number of paths.

Online narratives are experienced in a crowded environment filled with distractions, and the ease with which users can click to try an experience makes it just as easy for them to click and leave. They typically pay nothing, have little knowledge of the time-commitment of the project before they start it, and have no investment that might lead them to stay longer than a brief exploration.

Diamond Road Online

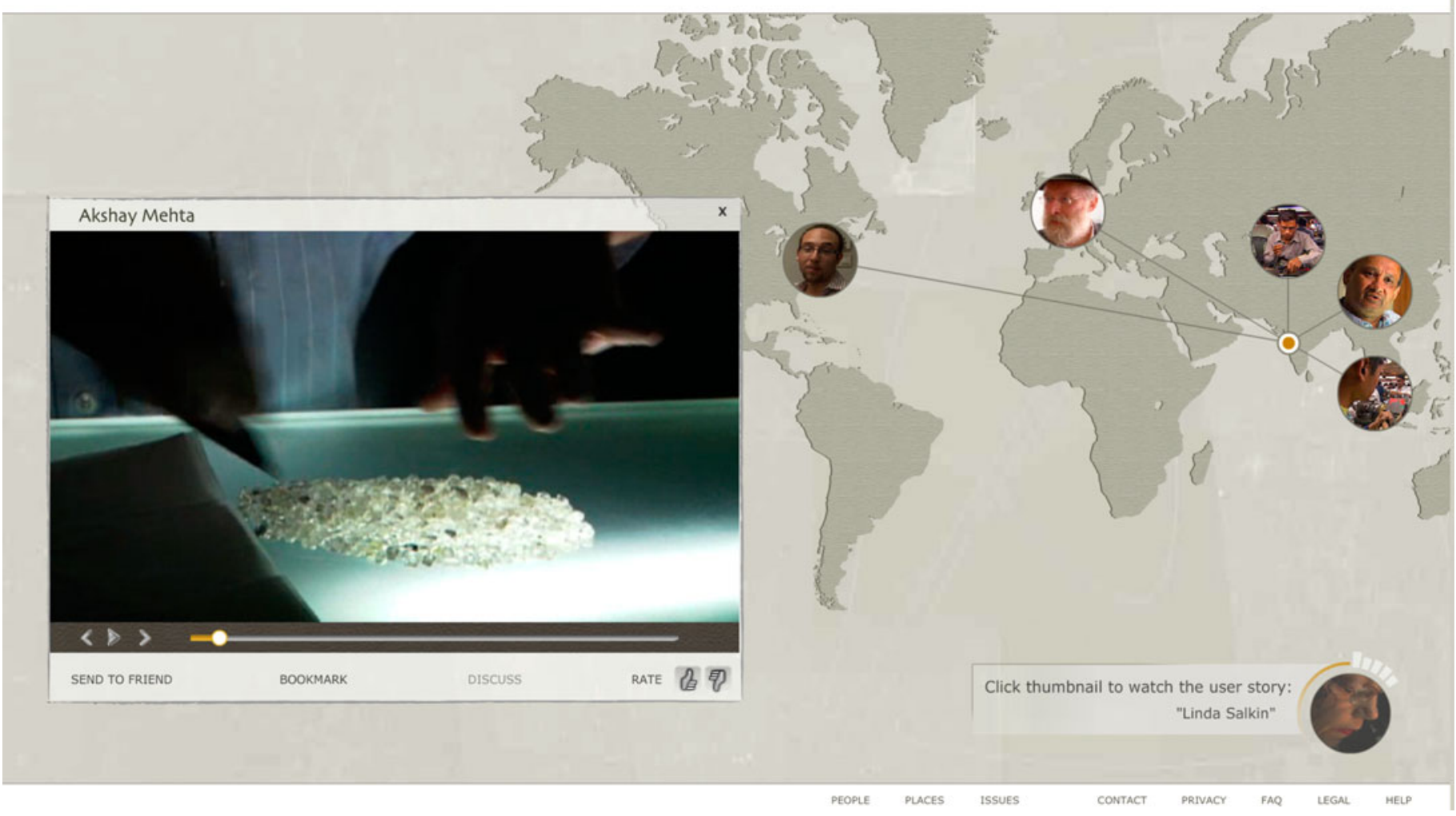

Diamond Road Online (Kensington Communications)

17 Richard Lachman and Charles Watson, 'Creating a User-steerable Media Presentation-system as a Canadian/Australian Distance-Learning Project,' Journal of Australasian Canadian Studies, 28, 2, 2010, 97-11.

18 Kensington Communications, "Diamond Road Online”, [Multi-format Interactive], 2008, http://www.diamondroad.tv. 
However, a broad scope and scale, much wider than that of film, can alter what the user thinks about the doc above and beyond the content they actually experience. It's a sense of complexity, or a sense of depth, that can convey an impression about the overall project. It is, in fact, the combination of Murray's procedural, spatial, participatory, and encyclopedic affordances: a narrative interface connected to a large collection of media. Database or data-driven doc projects such as Diamond Road Online, Jonathan Harris' The Whale Hunt, ${ }^{19}$ any of the K-films built with Florian Thalhoffer's Korsakow System, ${ }^{20}$ or the influential MIT Media Lab experiments with Elastic Boston and JBW ${ }^{21,22}$ all house large collections of content designed for non-linear and non-exhaustive user viewing.

\section{Time}

A key question is, of course, how much of that content users actually experience. When director Sergeo Kirby attempted to track down this data for POV Magazine he wrote "There is a reason producers will not give you this information, and that's because the numbers suck." ${ }^{33}$ Kirby quotes a spokesperson from the Canada Media Fund, who reports that the digital-documentary projects they fund have an average viewing length of between two to three minutes. The StoryCode organization interviewed critically acclaimed creators such as Lance Weiller (Body/Mind/Change), Elaine McMillan Sheldon (Hollow) and Theo Rigby (Immigrant Nation) ${ }^{24}$ about this question. When the average across projects was calculated, users were found to spend approximately 5 minutes with a site. None of the projects referenced contained only 5 minutes of content - indeed, most had more than an hour of media.

If a 90 minute film had most people leaving after 5 minutes, that would be considered a failure (and we would assume most people had had a negative experience of the film). It should be noted that limited access to data makes these numbers suspect - indeed, a greater sample-size and deeper analysis might reveal this as an aberration of the massdistribution of free digital content to what is still a niche audience. Deeper analysis might discount any sub-5-minute visitor as people not necessarily interesting in documentary at all, calculating averages only among those who are showing stronger interest through longer dwell-times. The digital documentary community should share more of this data in the interests of helping the industry develop.

However, and despite this incomplete data, we should also note that these short access times can still describe a positive experience. I suggest that many digital projects are about a sensation, an overall experience, as much as a narrative that emerges through aggregate story-beats. The combination of a unique interface, media design, and experience-design can result in a gestalt impression the way a static or digital work of art might. Film documentaries are focused on storytelling, which of course may also be at the core of a digital doc. However, digital projects also echo interactive art projects, in which coherent impression may be what users take away. This impression doesn't require an exhaustive review of all elements; sometimes, merely the knowledge that these elements exist can influence how we feel about the work or the subject-matter.

How would this mindset change our creative design? It doesn't necessarily follow that we should design 5-minute projects, as it may be the sense that of a vast depth, multiple stories, and comprehensive coverage that allows us to have a positive impression from a short experience. In Jonathan Harris' data-driven works there is very clearly no expectation that the user will experience all of the content - rather, by providing an interface that allows the user to dip in wherever they like, a sensation of complexity (perhaps linked to a sense of the breadth of human experience) is combined with a pleasure in the interface. The originality of the design is part of the sense of wonder - the intent becomes part of the discovery, and the interaction (prodding at the interface, gradually coming to understand what's

19 Jonathan Harris, 'The Whale Hunt,' interactive documentary, 2007, http://thewhalehunt.org/.

20 Florian Thalhofer, Korsakow System [Computer Program], Germany, 2011.

21 Michael Murtaugh, 'ConTour: Elastic Boston Demo', Video, 1995.

22 Michael Murtaugh, 'A Random Walk through the Twentieth Century', Interactive Website, 1995, http://ic.media.mit.edu/projects/JBW/.

23 Sergeo Kirby, 'The Interactive Paradox', POV Magazine, 2 July 2015, http://povmagazine.com/articles/view/the-interactive-paradox.

24 Michael Epstein and Michael Knowlton, 'The Promise and Realities of Creative Immersive Media Projects', StoryCode Report, http://ten. storycode.org/report.htm. 
going on) feels like the user is uncovering something for themselves. The tension between narrative and experience is one that creators with a film-background may, in particular, struggle with. The director-general of Canada's National Film Board suggests their involvement in interactive is a type of R\&D lab, with exploration laying groundwork for future storytellers. ${ }^{25}$ This type of experimentation means that the creator may not know precisely what the user experienced, yielding some aspects of control to the system. Not embracing this relationship brings the project back to the linear (and, again, may beg the question "why didn't you just make a film?"). If, instead of needing to convey details, the focus is on the impression and the feeling, a wider range of user-behaviours can be incorporated into the experience.

\section{Discovery andthe Magician's Force}

This, in turn, leads to another useful design opportunity: the feeling that the user is discovering something. I call this approach 'the magician's force'. In a magic trick, the performer may invite their mark to "pick a card... any card". Both parties know the user isn't really free to pick any card - the game is rigged - yet the audience-member feels unconstrained. When the magician completes the trick, the audience-member still has an experience of wonder, of magic, even though they know the outcome was predestined.

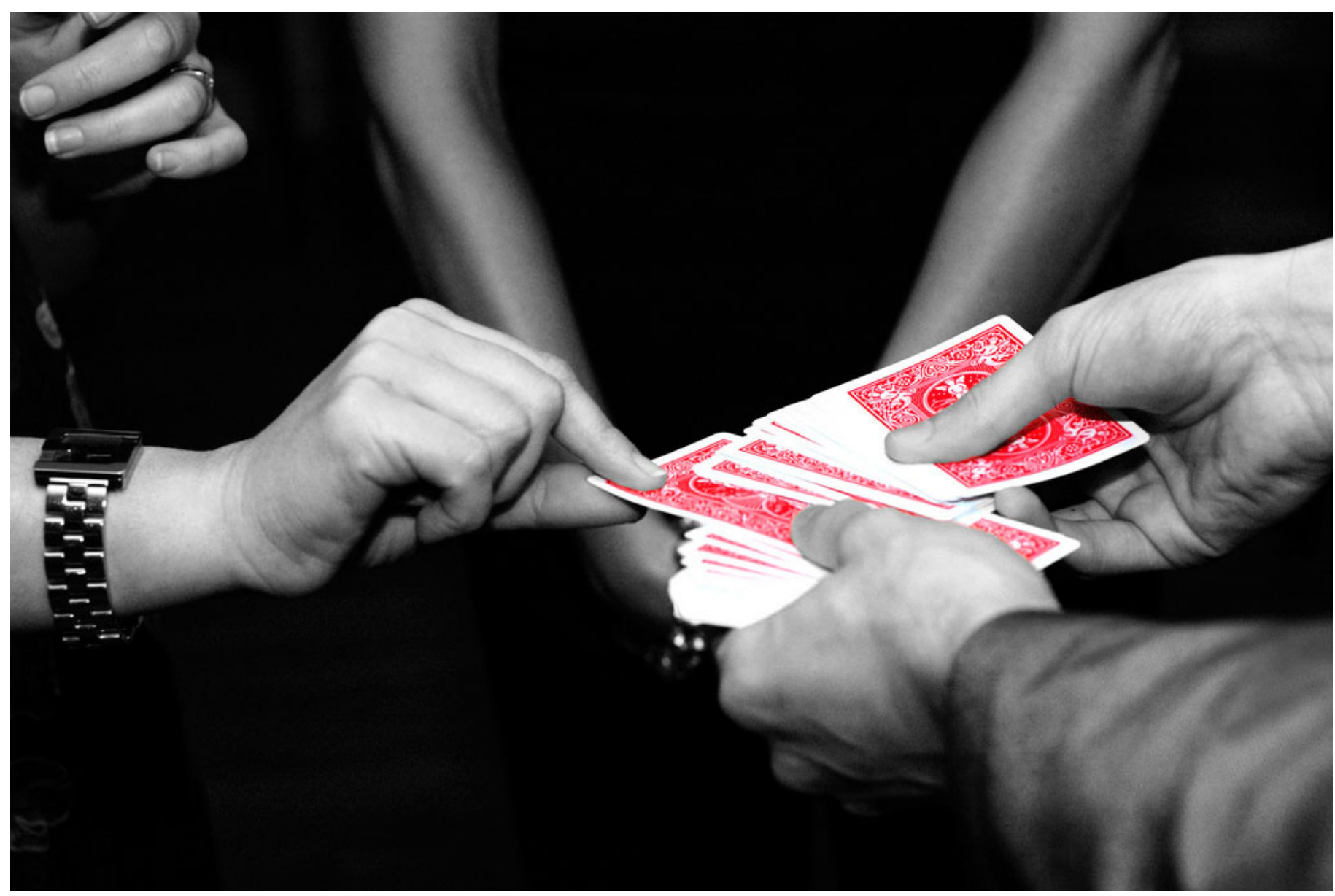

"Jean Luc Pick a Card" by KNLphotos2010 licnesed under CC by 2.0 
In digital projects, we really don't give the user total control. They can only go where we have established constraints, and they can only find what we have placed there. Yet this can be enough - the sense of wonder can still be cued. Where an interactive fiction project or a video-game may offer the suggestion that the user is controlling the outcome for example, choosing the course in a multi-path narrative, or repeating a level until a boss character is defeated - the digital doc typically offers no such expectation. The user assumes that a documentary approach precludes a changing outcome in the events depicted. Even explicitly game-like docs like Fort McMoney ${ }^{26}$ put the user in the role of an investigator, observing and interviewing, but not directly altering the events that unfold. So, then, the model is one of discovery and exploration among content rather than control over the world, characters, or future outcome. Where some projects have a more utility-based set of tools such as map-interfaces or slideshow-widgets, these too reinforce the feeling of exploring a collection of material. And yet, the dynamic isn't one of search. The user doesn't know the story, and isn't interrogating a toolset to extract specific information. Discovery and exploration need to be cued without making the user feel like they are being asked to make decisions without context, or to make meaningless choices. This tension between control and surprise is a delicate balance, and getting it right can be the key between an engaged user and an overwhelmed one.

C. Explore Al Fims Playlists Tralers HD Interactive Search

PINE POINT WAS

THE FIRST PLACE I

EVER WENT ALONE.

ch

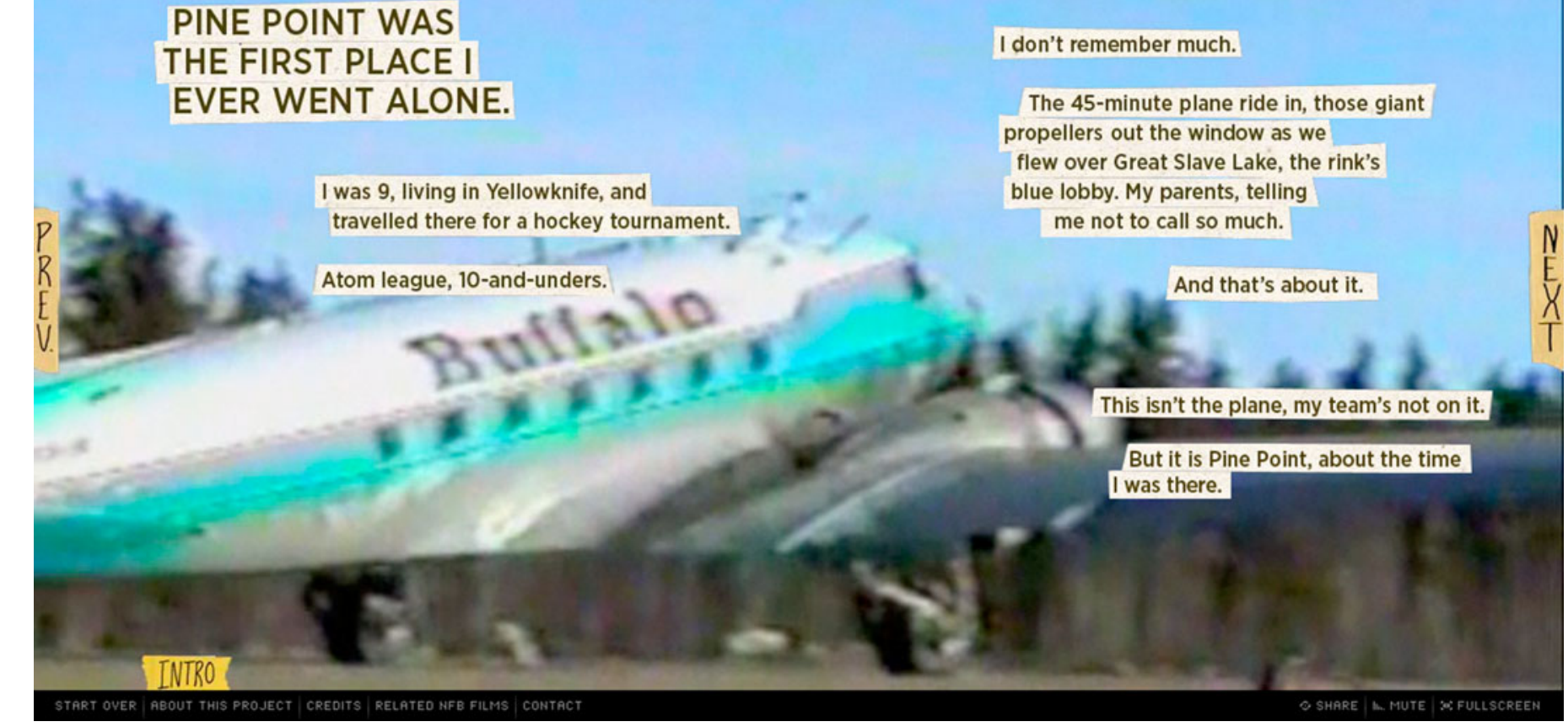

Welcome to Pine Point (NFB Interactive, 2011)

Welcome to Pine Point ${ }^{27}$ is a widely-cited project by Canada's National Film Board. Built in Flash, Pine Point explores ideas of history, nostalgia, and change in the context of archival photos, videos, and text about a vanishing small town in Canada. The project is essentially a linear narrative, and indeed, the creators, The Goggles, drew upon their experience in magazine and book-design for their guiding metaphor. The user doesn't really know what the overall subject matter is, and mysterious audio from the introductory screen is only later explained in context towards the conclusion of the piece. The experience is, instead, reminiscent of exploring a shoebox of photographs, diaries, and memories, with any transgressive feeling of voyeurism allayed by the owner voiceover that accompanies the user. The interface is easily readable, and while quite simplistic, suits the nostalgia-toned nature of the archival content. 
Even through the creators have, of course, pre-selected the available content and the behaviour of design-elements, this feeling of exploration and discovery can still be one of the key strengths of an interactive documentary. Refugee Republic $^{28}$ lets the user explore a quirky, hand-drawn StreetView-like representation of the 64,000-inhabitant Camp Domiz in Iraq. Users 'meet' various residents in the camp, learning about their lives and uncovering various quirks of the physical environment. The map isn't used as a direct index to content, but rather as an additional character in the overall design. Again, the framework isn't one of an index or of search, but rather an interface that allows users to learn quickly the capabilities, and then use them to navigate smaller narrative elements. The interface provides a narrative framework that knits the project together.

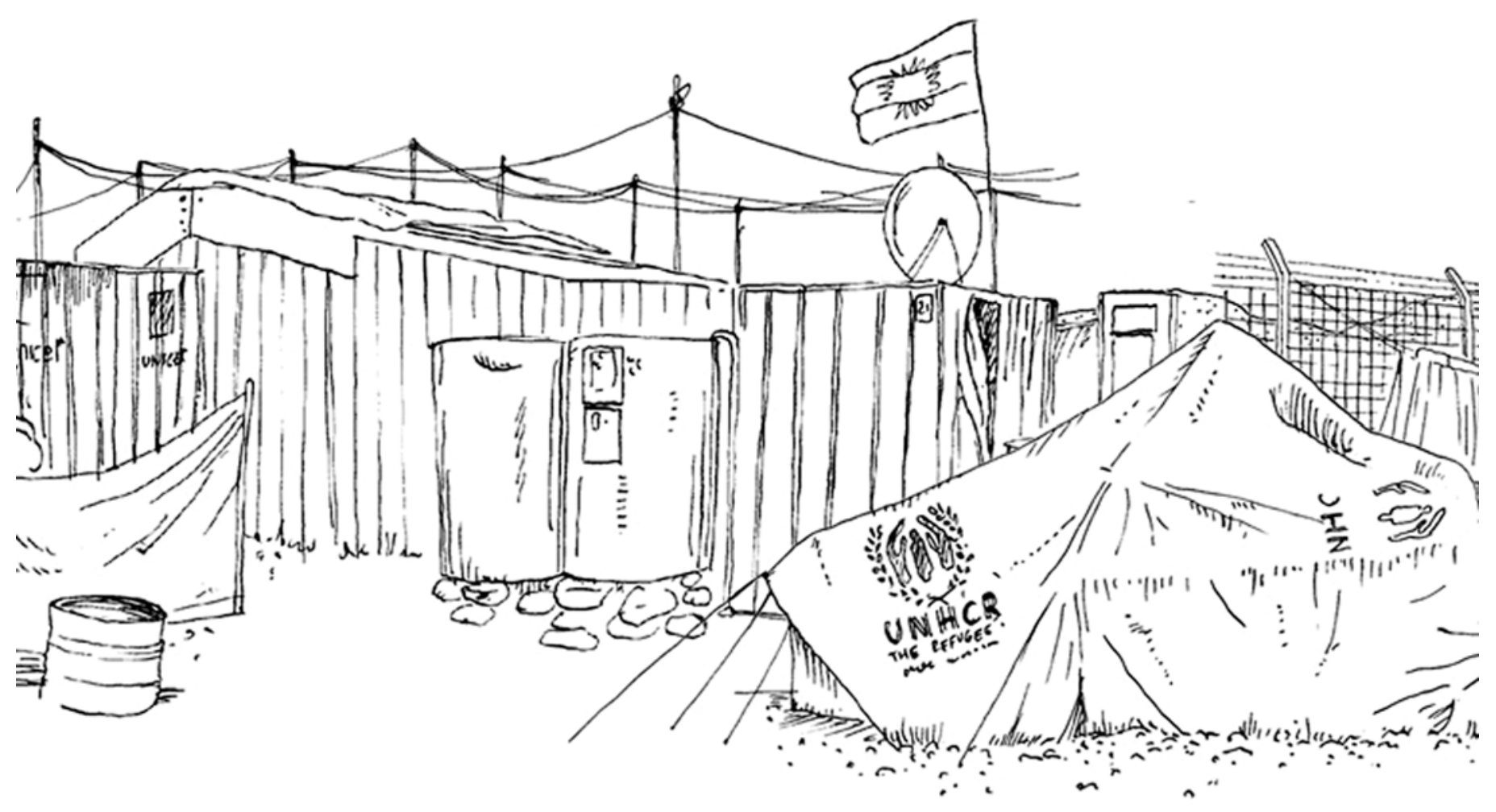

Refugee Republic (Submarine Channel)

\section{Double-Edged Affordances}

Critically, of course, digital technologies also afford capabilities that a documentarian may want to discourage as part of the design of the experience. It is effortless for users to become distracted; without the constraints of a darkened theatre (or the sunk-cost of a ticket), users face a multi-function digital environment with competing demands for attention. Suggesting users view a project as full-screen not only increases the impact of the visuals, it blocks out potential distractions. More difficult to overcome is the paradox of choice. The promise of a digital doc is to encourage exploration, communication, and complexity; at the same time, these modes afford distraction, divided attention, and shallow engagement. If a project encourages users to respond via Twitter, they may move to checking their Twitter feed instead. If presented with buttons and control-widgets, users may click for the sake of clicking, trying to figure out the meta-narrative at the cost of engagement with the narrative itself. 
Originality and creativity in an interface can increase the esthetic impact of the project, perhaps at the cost of usercomfort and predictability. Digital documentaries tread a fine line between interactive art and industrial production. They are heir to some of the ethics of non-fiction storytelling, and, for many, the language of film-editing; however, they also seem to strive for a unique role as an original experience. Few projects repeat the interface-choices of others. Most projects are one-offs, and being unlike others is part of the overall impact. If this goal leaves a user confused about what is being asked of them, this could in turn lead to resistance, confusion, and the desire to simply 'sit back and watch something'.

\section{Production, Marketing, and Distribution}

While digital technologies can democratize production (through cheap HD cameras, open-source editing/coding) and distribution (through cheap webhosting, affordable broadband, free streaming on YouTube or Vimeo), they also problematize content discovery, crash existing business models, and complicate signifiers of quality, trust, tone, or approach. An interactive narrative offers the promise that my choices in the experience will lead me to a variant that appeals to my particular interests in the story. In turn, that comes at the loss of a shared experience I can discuss with a friend or have with a group. Allowing users to comment and share their responses online can be incredibly gratifying for a documentarian, who may otherwise get their only feedback from Nielson ratings or Q\&A's at festival screenings. The tradeoff is, of course, the vitriol of YouTube comment-threads, the negative publicity from single-issue critics unbounded by journalistic ethics, and the chilling effects of an unprotected relationship with advertisers, brands, and sponsors. New platforms and technologies offer exciting creative possibilities, and worrisome risks to the lifespan, archivability, reliability, and audience-reach for a project.

Finally, it is worth noting that, while critical acclaim and festival installations will continue to go to digital documentaries that break ground in interface or creative design, there are significant opportunities for more conventional projects to innovate in how they create and communicate their work. The conventional filmed doc Ready, Set, Bag (2008) used the online Groupon platform to convince independent theatres to book the film. ${ }^{29}$ Groupon allows people to commit to buy something without actually being billed unless a certain number are sold. With this risk-free pre-sales strategy, the filmmakers could demonstrate ticket-sales before the theatre-owners had to commit to the screening or the film-goers to transfer funds.

In the modern attention-economy, Jenkins, Ford, and Green indicate the importance of making content easily sharable, in a way that gives social value to the one who posts it or strengthens the bonds between a particular in-group. ${ }^{30}$ This concept of spreadable media can be seen in action with John Oliver's investigative rants for HBO's Last Week Tonight. Rather than the media corporation stamping out the clips' inevitable appearance online as copyright violations, Oliver's team makes the segments available as highly spreadable YouTube clips, boosting his presence and gaining a reach most mainstream journalists would envy. The focus on a single issue in each rant means that Facebook friends work the clips into their ongoing topical conversations, or pass them along to friends with similar politics.

\section{Conclusions}

The process of creating a digital documentary is an experimental one. Rapid shifts in user behaviour, creative design, technology platforms, and design conventions occur month to month, year over year. Creators must integrate creative and functional design across interface, production, distribution, and experience, above and beyond the narrative at the core of their work. As such, it's important for teams to be deliberate and thoughtful about the overall design of their

29 Suzy Evan, 'Groupon Cooks Up Some Entertainment Partnerships,' Fast Company, August 6, 2010, http://www.fastcompany.com/1678091/ groupon-cooks-some-entertainment-partnerships.

30 Henry Jenkins, Sam Ford, and Joshua Green, Spreadable media: Creating value and meaning in a networked culture, NYU Press, 2013. 
works, and to develop an understanding of the user experience as a coherent whole. It is hoped that the opportunities defined here provide some inspiration for teams to develop deliberate strategies in their experimentation.

\section{B i o g r a p h y}

Dr. Richard Lachman directs the Zone Learning incubator network, Research Development for the Faculty of Communication and Design, and the Experiential Media Institute (formerly the Transmedia Research Centre), all at Ryerson University in Toronto, Canada. He is an Associate Professor, Digital Media in the RTA School of Media. His work in transmedia has garnered a Gemini, CNMA and Webby Honouree awards, and he has lead collaborative design exercises with UNICEF, TIFF, Penguin UK, Kobo, the CRTC, and others. His areas of research include transmedia storytelling, digital documentaries, augmented/locative/VR experiences, mixed realities, and collaborative design thinking. 